\title{
Comparison of various isostatic marine gravity disturbances
}

\author{
Robert Tenzer ${ }^{1, *}$, Mohammad Bagherbandi $^{2,3}$ and Lars E SjöBerg ${ }^{2}$ \\ ${ }^{1}$ Institute of Geodesy and Geophysics, School of Geodesy and Geomatics, Wuhan University, \\ 129 Luoyu Road, Wuhan, China. \\ ${ }^{2}$ Division of Geodesy and Geoinformatics, Royal Institute of Technology (KTH), SE-10044 Stockholm, Sweden. \\ ${ }^{3}$ Department of Industrial Development, IT and Land Management University of Gävle, SE-80176 Gävle, Sweden. \\ *Corresponding author.e-mail: rtenzer@sgg.whu.edu.cn
}

We present and compare four types of the isostatic gravity disturbances compiled at sea level over the world oceans and marginal seas. These isostatic gravity disturbances are computed by applying the AiryHeiskanen (AH), Pratt-Hayford (PH) and Vening Meinesz-Moritz (VMM) isostatic models. In addition, we compute the complete crust-stripped (CCS) isostatic gravity disturbances which are defined based on a principle of minimizing their spatial correlation with the Moho geometry. We demonstrate that each applied compensation scheme yields a distinctive spatial pattern in the resulting isostatic marine gravity field. The AH isostatic gravity disturbances provide the smoothest gravity field (by means of their standard deviation). The AH and VMM isostatic gravity disturbances have very similar spatial patterns due to the fact that the same isostatic principle is applied in both these definitions expect for assuming a local (in the former) instead of a global (in the latter) compensation mechanism. The PH isostatic gravity disturbances are highly spatially correlated with the ocean-floor relief. The CCS isostatic gravity disturbances reveal a signature of the ocean-floor spreading characterized by an increasing density of the oceanic lithosphere with age.

\section{Introduction}

According to classical isostatic models, it is assumed that the topographic mass surplus and the oceanic mass deficiency are compensated by either a variable depth or density of compensation. The Pratt-Hayford ( $\mathrm{PH})$ isostatic model is based on adopting a constant depth of compensation while considering a variable compensation density (Pratt 1855; Hayford 1909; Hayford and Bowie 1912). In the Airy-Heiskanen (AH) isostatic model, a constant compensation density is assumed, while a depth of compensation is variable (Airy 1855; Heiskanen and Vening Meinesz 1958). Whereas the AH model can reproduce relatively realistically, the isostasy especially under significant orogens (where the isostatic mass balance is mainly controlled by a varying depth of compensation), the PH model approximates more realistically the compensation mechanism under oceans (where the isostatic mass balance is mainly governed by a varying density of compensation). For this reason, some authors recommended using the $\mathrm{PH}$ model over oceans and the AH model on land (e.g., Wild and Heck 2004; Makhloof 2007). Moreover, both these isostatic schemes assume only a local compensation. Vening Meinesz (1931) modified the AH theory by introducing a regional isostatic compensation based on a thin plate lithospheric flexure model (Watts 2001). Moritz (1990)

Keywords. Bathymetry; Bouguer gravity correction; isostasy; marine gravity; gravimetric forward modelling. 
further generalized the Vening Meinesz's inverse problem by assuming a global compensation mechanism, called herein the Vening Meinesz-Moritz (VMM) problem of isostasy, and adopted a spherical reference surface (see also Abd-Elmotaal 1991, 1993, 2000, 2004; Sjöberg 2009, 2013; Bagherbandi et al. 2013). Tenzer et al. (2009a, 2012b, d) defined the complete crust-stripped (CCS) isostatic model of which definition was given based on a principle of minimizing the spatial correlation between the isostatic gravity disturbances and the Moho geometry. They demonstrated that these isostatic gravity disturbances are obtained from the Earth's gravity disturbances after removing gravitational signals of crustal density heterogeneities and Moho geometry.

All these four isostatic models were formulated based on assuming that the isostatic mass balance is attained within the Earth's crust. The isostatic mass balance, however, depends on several different factors including loading and effective elastic thickness, rigidity, rheology of the lithosphere and viscosity of the asthenosphere (e.g., Watts 2001). Moreover, the glacial isostatic adjustment, present-day glacial melting, plate tectonics, mantle convection and other geodynamic processes contribute to the overall isostatic balance. Kaban et al. (1999), for instance, demonstrated that the isostatic mass balance takes place not only within the crust but eventually within the whole lithosphere. The isostatic gravity disturbances also contain a long-wavelength signal of the mantle density heterogeneities including the core-mantle boundary zone (cf. Sjöberg 2009). Braitenberg et al. (2006) demonstrated that the misfit of the isostatic assumption of the Moho interface to a longwavelength part of the gravity field is explained by large marine sedimentary basins and rigidity variations of the crustal plate. Within the oceanic lithosphere, the isostatic Bass balance is also controlled by thermal cooling caused by the oceanfloor spreading. According to the theory of thermal cooling, the thickness of the (thermal) oceanic lithosphere model is increasing with age. At the same time, the density increase due to a thermal volumetric contraction of the oceanic lithosphere is isostatically compensated by the increasing oceanfloor depth (see e.g., Parsons and Sclater 1977). This model assumes that the isostatic equilibrium within the whole oceanic lithosphere is attained by a changing density while a depth of compensation is constant (e.g., Turcotte and Schubert 2002, Chapter 5).

In this study, we compared the $\mathrm{AH}, \mathrm{PH}, \mathrm{VMM}$ and CCS isostatic gravity disturbances computed over the world oceans and marginal seas. The application of more complex isostatic models, which account for the mantle density heterogeneities and other geodynamic factors (i.e., crustal loading due to marine sediments, thermal cooling of the oceanic lithosphere), is out of the scope of this study. We further investigated a spatial smoothness of these isostatic gravity disturbances and compared their spatial correlations with the ocean-floor relief (and age). Our analysis was restricted to a longwavelength part of the isostatic gravity spectra complete to degree 250 of spherical harmonics. The isostatic gravity disturbances are briefly reviewed in section 2 . The results are presented in section 3 and discussed in section 4. The conclusions are given in section 5 .

\section{Isostatic gravity disturbances}

With reference to Tenzer and Bagherbandi (2012), we define the isostatic gravity disturbance $\delta g^{\mathrm{i}}$ as follows:

$$
\delta g^{\mathrm{i}}=\delta g^{\mathrm{TB}}+g^{\mathrm{c}},
$$

where $\delta g^{\mathrm{TB}}$ denotes the refined Bouguer gravity disturbance, and $g^{\mathrm{c}}$ is the isostatic reduction (e.g., Moritz 1990, Chapter 8). The refined Bouguer gravity disturbance $\delta g^{\mathrm{TB}}$ is obtained from the gravity disturbance $\delta g$ after applying the topographic and bathymetric gravity corrections. Hence

$$
\delta g^{\mathrm{TB}}=\delta g-g^{\mathrm{T}}+g^{\mathrm{B}},
$$

where $g^{\mathrm{T}}$ and $g^{\mathrm{B}}$ are the gravitational attractions of topography and seawater density contrast, respectively.

It is worth mentioning that in classical definition of the simple planar Bouguer gravity anomaly (e.g., Heiskanen and Moritz 1967), the topography is approximated by an infinite Bouguer plate. Under this planar approximation of topography, the Bouguer gravity reduction at sea level equals zero, because this reduction is defined as a function of the topographic height of a computation point. If a definition of the Bouguer gravity reduction also includes the planar terrain correction, the computed effect of topography at sea level is non-negative, because the values of the planar terrain correction are also non-negative. Moreover, the planar terrain correction could not be neglected over marine areas, especially along marginal seas in vicinity of large mountain ranges where its values could reach several dozens of mGal. Similarly, in spherical approximation, the topographic gravity correction has to be taken into consideration in computing the marine Bouguer gravity data. This was demonstrated, for instance, by Tenzer et al. (2015a). They estimated that the topographic gravity correction computed at sea level over the world oceans and marginal seas varies within -16 to $205 \mathrm{mGal}$. 
In classical definitions of the $\mathrm{AH}, \mathrm{PH}$ and $\mathrm{VMM}$ isostatic gravity field (e.g., Heiskanen and Moritz 1967; Moritz 1990), the gravity corrections due to glacial ice, sediments and consolidated crust are typically disregarded. In contrast, the application of these gravity corrections (accounting for crustal density heterogeneities) is incorporated explicitly in definition of the consolidated cruststripped gravity disturbances (cf. Tenzer et al. 2009a, 2015b) in order to attain a maximum spatial correlation of these refined gravity data with the Moho geometry (cf. Tenzer et al. 2009b). For this reason, we applied these additional gravity corrections only in computing the consolidated crust-stripped gravity disturbances. The AH, PH and VMM isostatic gravity disturbances were then obtained from the refined Bouguer gravity disturbances after applying the respective isostatic reductions (equation 1). The consolidated cruststripped gravity disturbances were used to compute the CCS isostatic gravity disturbances. The CCS isostatic reduction was defined so that it minimizes a spatial correlation between the isostatic gravity disturbances and the Moho geometry (cf. Tenzer et al. 2012d).

In this study, the gravity corrections and respective corrected gravity disturbances were computed using the expressions given in Tenzer et al. (2012a). The computation of the $\mathrm{AH}$ and $\mathrm{PH}$ isostatic reductions was realized according to the expressions derived by Sjöberg (1998a, b). For theoretical details of these isostatic models we refer readers also to studies of Lambeck (1988), Rummel et al. (1988) and Tsoulis (2001). The VMM isostatic reduction was evaluated according to the expressions given in Sjöberg (2009). The CCS isostatic gravity disturbances were defined in Tenzer et al. (2012b, d).

\section{Results}

We computed the isostatic gravity disturbances over the world oceans and marginal seas on a $1 \times 1$ arc-deg spherical grid at sea level using the GOCO03S gravity model (Mayer-Guerr et al. 2012), the DTM2006.0 solid topography and ice thickness data (Pavlis et al. 2007) and the CRUST2.0 global seismic crustal model (Bassin et al. 2000). The gravity disturbances and the gravity corrections due to topography, bathymetry and ice were computed with a spectral resolution complete to a spherical harmonic degree of 250 . The gravity corrections due to sediments and consolidated crust were evaluated up to degree 90 of spherical harmonics, compatible with a $2 \times 2$ arc-deg spatial resolution of the CRUST2.0 model. The AH, PH and VMM isostatic reductions were computed complete to degree 250 of spherical harmonics and the spectral resolution up degree 90 was used to evaluate the CCS isostatic reduction using the CRUST2.0 Moho depths. Since the Moho geometry beneath the oceanic crust is typically smooth, the omission errors due to disregarding the spherical harmonics between degrees 91 and 250 should not have any significant impact on a spectral resolution of the resulting CCS isostatic gravity disturbances. The $\mathrm{AH}, \mathrm{PH}, \mathrm{VMM}$ and CCS isostatic gravity disturbances, therefore, comprise spectral information up to a similar degree of spherical harmonics.

The gravity disturbances were computed from the GOCO03S coefficients after subtracting the GRS80 coefficients of normal gravity field (Moritz 2000). The DTM2006.0 coefficients were used to compute the topographic and bathymetric gravity corrections. The average density of the upper continental crust of $2670 \mathrm{~kg} / \mathrm{m}^{3}$ (cf. Hinze 2003) was adopted for a definition of the topographic density. The seawater density distribution was approximated by a depth-density seawater equation (see Gladkikh and Tenzer 2011; Tenzer et al. 2011, 2012c). The topographic and bathymetric corrections were applied to the GOCO03S gravity disturbances. The resulting refined Bouguer gravity disturbances are shown in figure 1 . These gravity disturbances are mostly positive (over the world oceans and marginal seas) and vary between -54 and $1042 \mathrm{mGal}$ (with a mean of $399 \mathrm{mGal}$ and a standard deviation of $143 \mathrm{mGal}$ ). The largest values of these gravity disturbances were detected along oceanic trenches characterized by the largest bathymetric depths. The gravity values decrease over abyssal planes and reach minima along marginal seas. This gravity pattern thus closely resembles the ocean-floor relief. This is shown in figure 2, where we plotted the relation between the refined Bouguer gravity disturbances and the bathymetric depths.

The computation of the consolidated cruststripped gravity disturbances was realized by applying additional (stripping) gravity corrections to the refined Bouguer gravity disturbances. Here we considered the gravity corrections due to density contrasts of the continental ice sheets, sediments and within remaining consolidated crust (down to the Moho interface). The DTM2006.0 topographic and ice-thickness data were used to compute the ice gravity correction according to the procedure described in Tenzer et al. (2010). The CRUST2.0 discrete data of the (soft and hard) sediment thickness, depth and density were used to generate the coefficients of the sediment density contrast layers. We then applied the spherical harmonic analysis to compute the sediment gravity correction from these coefficients. The same procedure was applied to compute the consolidated crust 


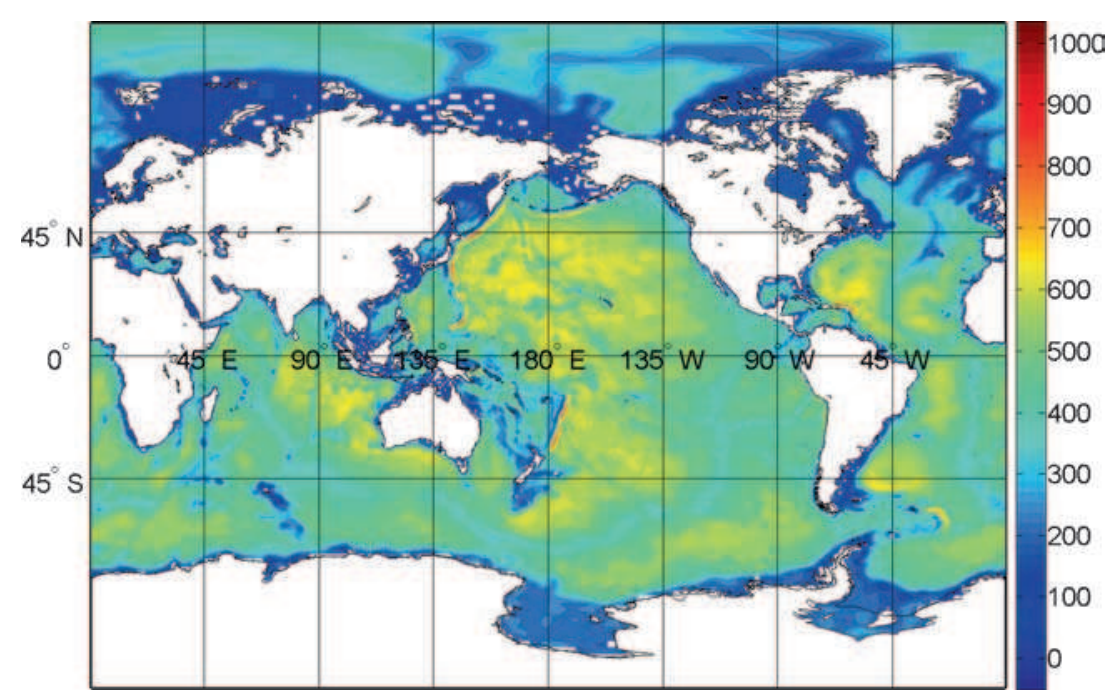

Figure 1. Bouguer gravity disturbances (values are in $\mathrm{mGal}$ ).

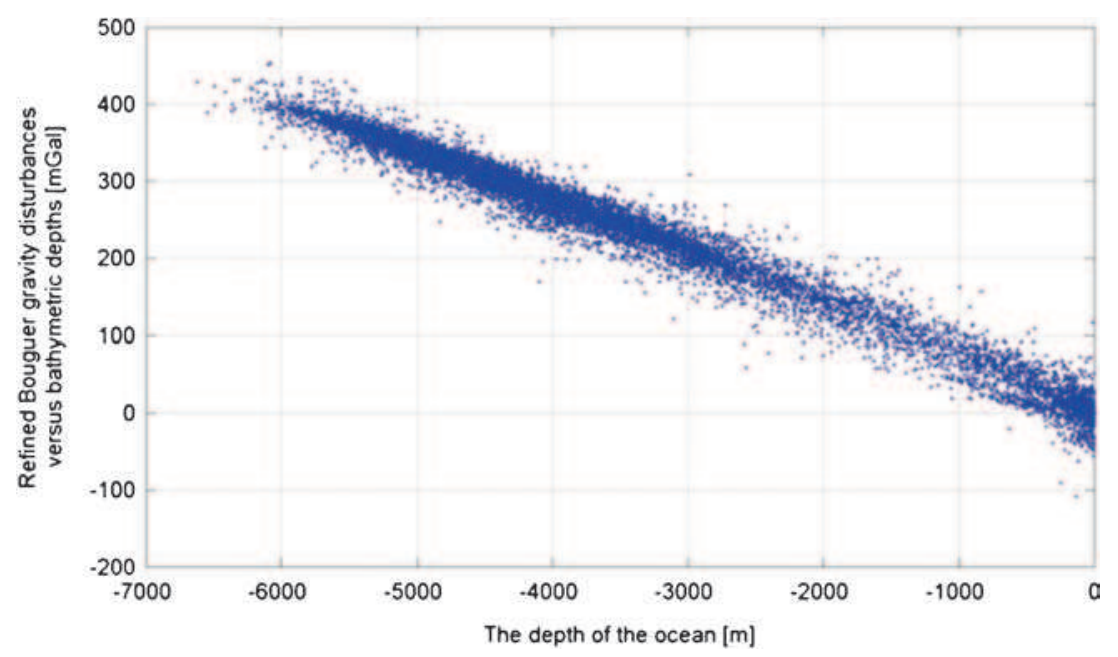

Figure 2. Scatter plot of the refined Bouguer gravity disturbances with respect to the bathymetric depths.

gravity correction from the CRUST2.0 discrete data of the (upper, middle and lower) consolidated crust thickness, depth and density.

The ice gravity correction is shown in figure 3 . The gravitational contribution of the continental ice sheets is significant in proximity of Greenland and Antarctica, where it reaches maxima up to $63 \mathrm{mGal}$ (with a mean of $2 \mathrm{mGal}$ and a standard deviation of $4 \mathrm{mGal}$ ). The sediment gravity correction is shown in figure 4 . This correction is positive everywhere and varies between 12 and $134 \mathrm{mGal}$ (with a mean of $38 \mathrm{mGal}$ and a standard deviation of $23 \mathrm{mGal}$ ). The largest values of this correction, with maxima locally exceeding $100 \mathrm{mGal}$, are seen along continental slopes, especially over large accumulations of marine sediments due to a river discharge of Mississippi, Ganga and Nile. Moreover, the signatures of the Bengal, Indus, and other deep-sea fans (i.e., large marine sedimentary accumulations deposited on the slope and adjacent sea floor originated during ice-age climatic episodes) are also pronounced in the gravity map of sediment correction. Large values of this correction are also seen throughout large parts of the Arctic Ocean. The consolidated crust gravity correction is shown in figure 5. This gravitational contribution of the anomalous crustal density structures varies from -576 to $461 \mathrm{mGal}$ (with a mean of $179 \mathrm{mGal}$ and a standard deviation of $197 \mathrm{mGal}$ ). These three stripping gravity corrections were applied to the refined Bouguer gravity disturbances. The result is shown in figure 6 . The consolidated crust-stripped gravity disturbances are mainly positive and vary between -718 and $486 \mathrm{mGal}$ (with a mean of 179 $\mathrm{mGal}$ and a standard deviation of $198 \mathrm{mGal}$ ). Both gravity data, the refined Bouguer and consolidated crust-stripped gravity disturbances, are highly spatially correlated with the ocean-floor relief (cf. 


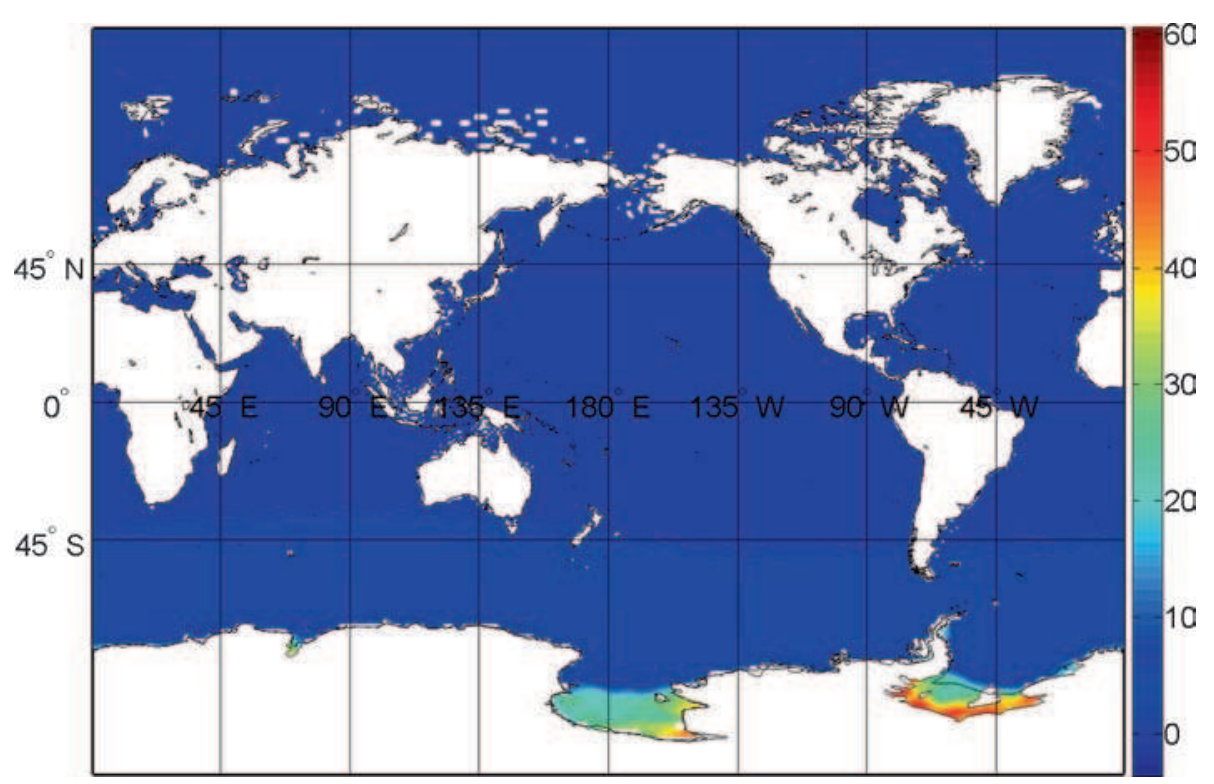

Figure 3. Ice gravity correction (values are in mGal).

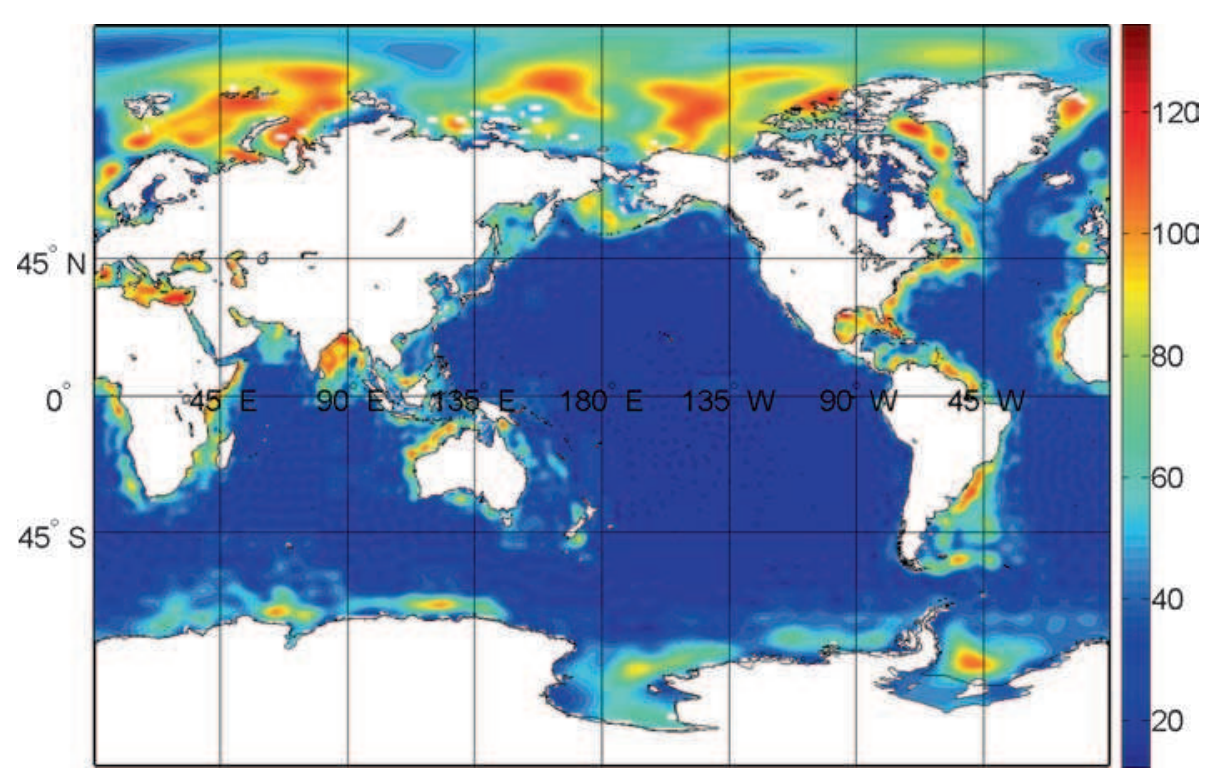

Figure 4. Sediment gravity correction (values are in mGal).

figures 1 and 6 ). The consolidated crust-stripped gravity disturbances, however, comprise the additional Moho signature. This is particularly evident in a more pronounced contrast between the oceanic and continental lithosphere along marginal seas in the spatial pattern of the consolidated crust-stripped gravity disturbances attributed to a thin oceanic crust compared to a much thicker continental crustal structures.

We further computed four types of the isostatic reductions. The resulting isostatic gravity disturbances are shown in figure 7 and their statistical summary is given in table 1 .

\section{Discussion}

The investigated isostatic gravity disturbances have different spatial distributions (see figure 7) and statistical properties (see table 1), specified by their mean value, range (i.e., minimum and maximum values) and spatial smoothness (i.e., their standard deviation). The AH, PH and VMM isostatic gravity disturbances have similar mean values (between -264 and $-218 \mathrm{mGal}$ ). Moreover, their values are mostly negative. In contrast, the CCS isostatic gravity disturbances are everywhere positive and their mean value is $758 \mathrm{mGal}$. As seen 


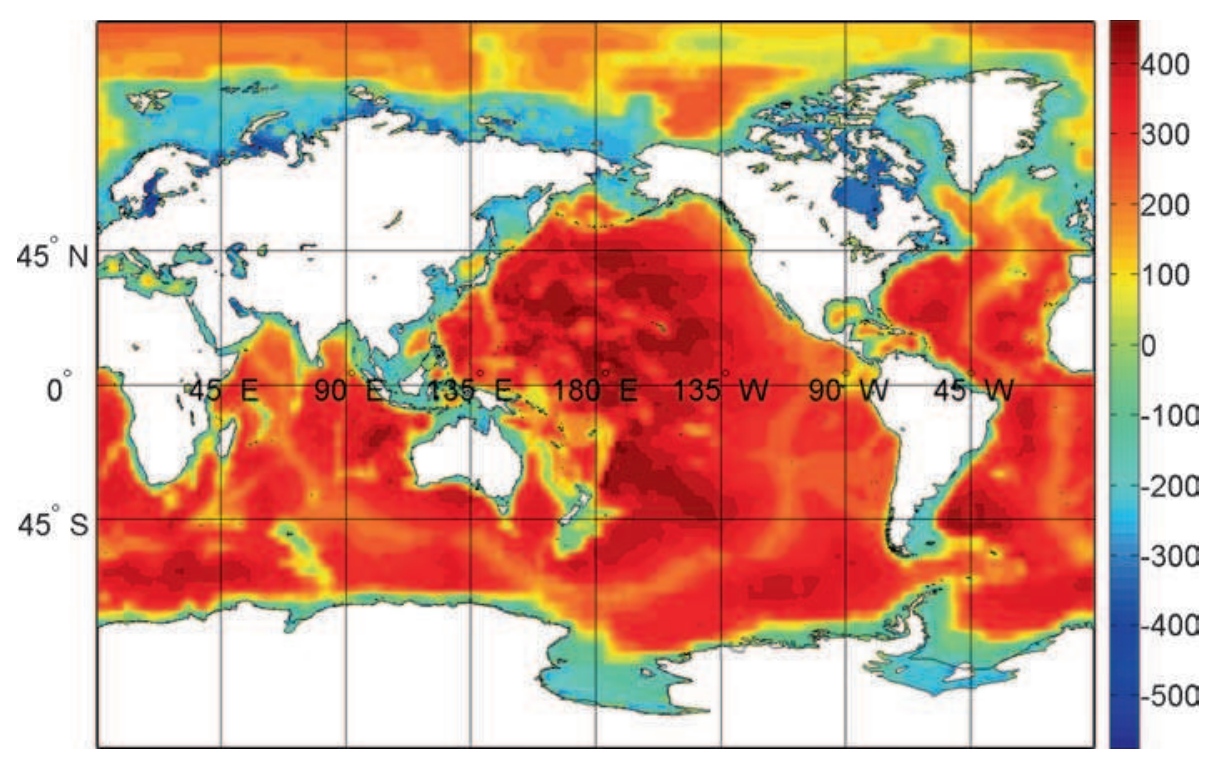

Figure 5. Consolidated crust gravity correction (values are in mGal).

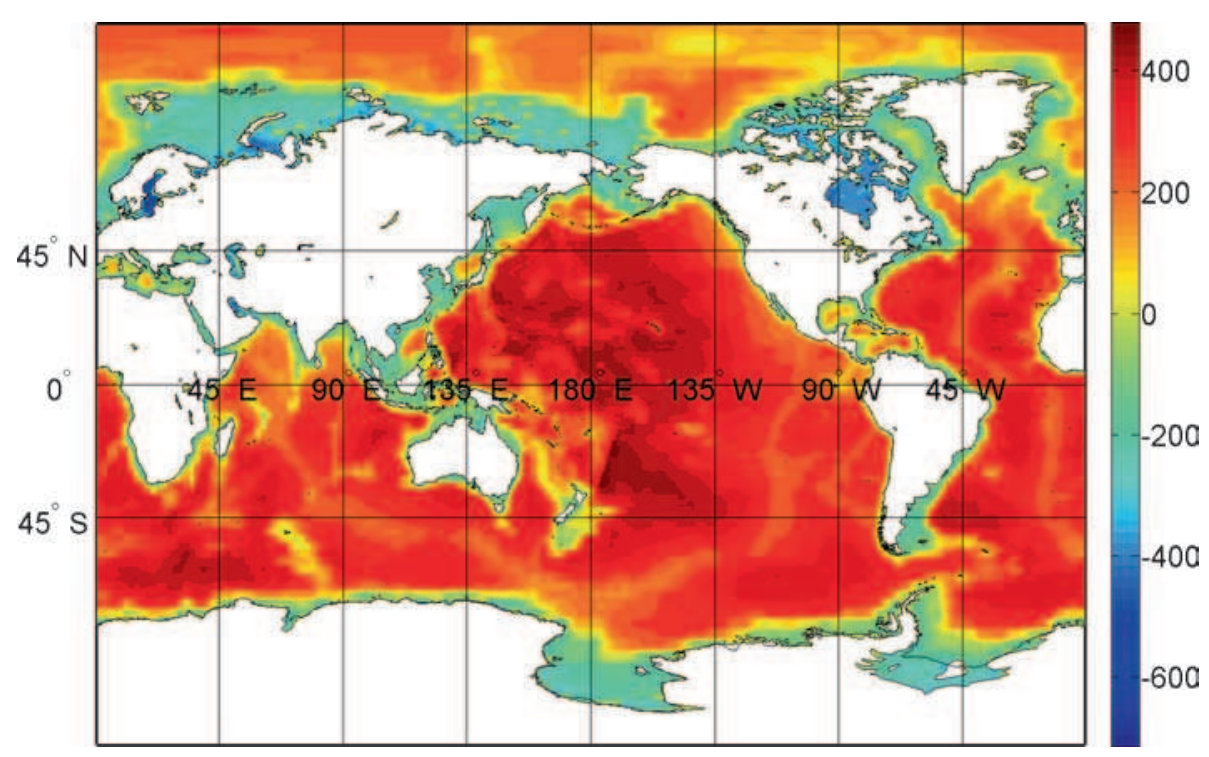

Figure 6. Consolidated crust-stripped gravity disturbances (values are in mGal).

in table 1 , the $\mathrm{AH}$ and $\mathrm{PH}$ isostatic gravity disturbances have a similar range of values of 675 and $705 \mathrm{mGal}$, respectively. The VMM isostatic gravity disturbances are distributed within the largest interval of $983 \mathrm{mGal}$. The CCS isostatic gravity disturbances have, on the other hand, the smallest range of values of only $551 \mathrm{mGal}$. Furthermore, the standard deviations in table 1 indicate that the application of the $\mathrm{AH}$ model provided the smoothest marine gravity field and the standard deviation of the $\mathrm{AH}$ isostatic gravity disturbances is only $46 \mathrm{mGal}$. Similarly, the VMM and CCS isostatic gravity disturbances are relatively smooth with the standard deviations of 53 and 63 $\mathrm{mGal}$, respectively. In contrast, the $\mathrm{PH}$ isostatic gravity disturbances have a much larger standard deviation of $125 \mathrm{mGal}$.

To better understand a spatial behaviour of these isostatic gravity disturbances, we further investigated their correlation with respect to the ocean-floor relief. Scatter plots are shown in figure 8. As seen in figure 8(b), the $\mathrm{PH}$ isostatic gravity disturbances systematically decrease with the increasing bathymetric depth at a rate of horizontal spatial change of about $-80 \mathrm{mGal}$ per $1 \mathrm{~km}$ of depth. In contrast, the AH, VMM and CCS isostatic gravity disturbances have an opposite trend and their horizontal spatial changes relative to the bathymetric depth are much smaller. These three isostatic gravity disturbances increase at a 

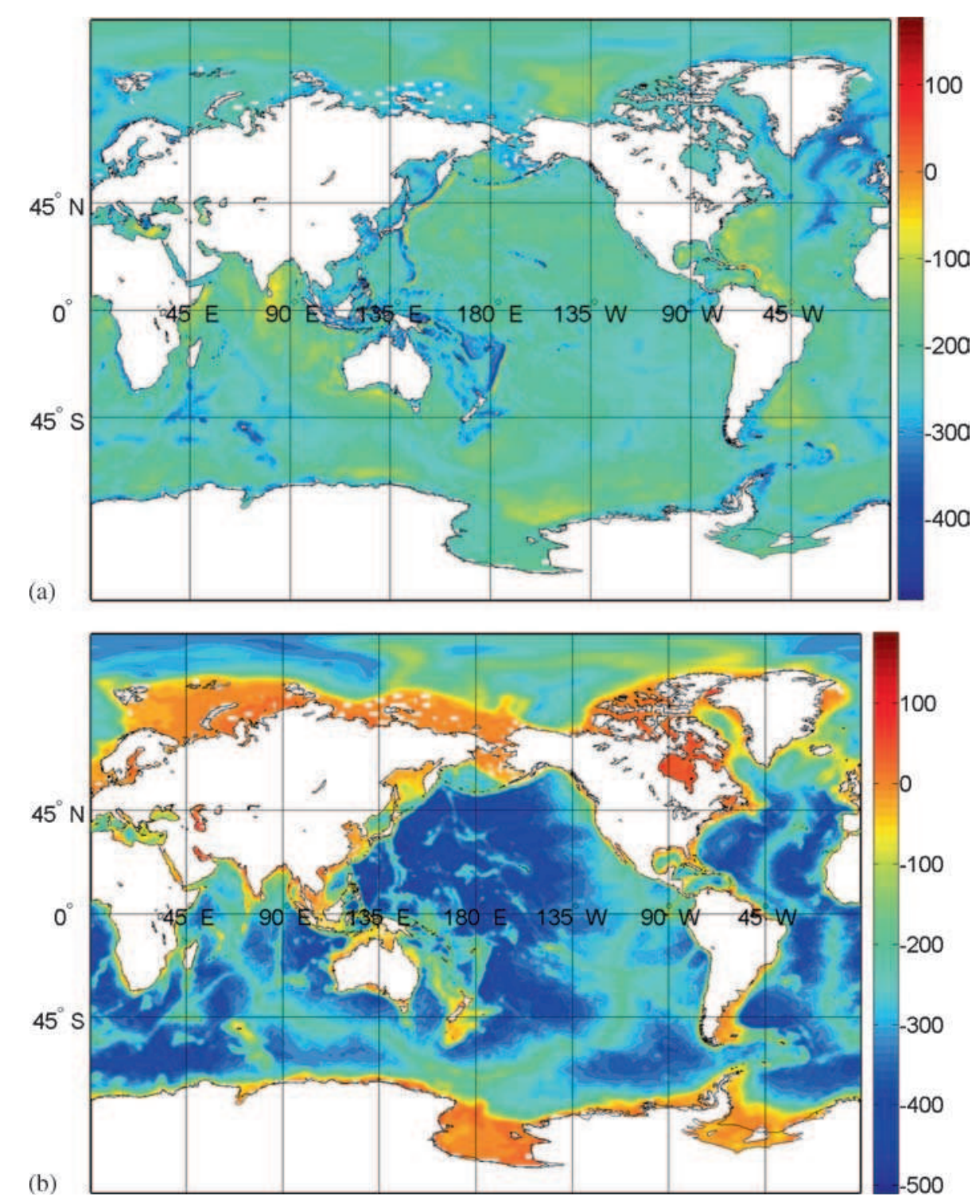

Figure 7. Isostatic marine gravity data: (a) Airy-Heiskanen, (b) Pratt-Hayford, (c) Vening Meinesz-Moritz, and (d) complete crust-stripped isostatic gravity disturbances (values are in mGal).

similar rate of about $30 \mathrm{mGal}$ per $1 \mathrm{~km}$ of depth (cf. figure 8a, c, d). This analysis also explained why the $\mathrm{PH}$ isostatic gravity disturbances have the largest standard deviation. As seen in figure 8(b), most of these gravity values are systematically distributed at a large interval from about -450 to $50 \mathrm{mGal}$. Despite $\mathrm{AH}$ and $\mathrm{PH}$ isostatic gravity disturbances having a similar range of values, most of the AH isostatic gravity disturbances are systematically distributed only within the interval from about -350 to $-150 \mathrm{mGal}$ (see figure 8a). A similar pattern of systematically distributed values within a relatively small interval is seen also in the VMM and CCS isostatic gravity disturbances (cf. figure 8c, d).

Comparison of the gravity maps in figure 7(a and c) revealed some similarities in spatial patterns of the $\mathrm{AH}$ and VMM isostatic gravity disturbances.
This is also evident from the scatter plots in figure 8 (a and $\mathrm{c}$ ) and the statistics in table 1. Both these isostatic gravity disturbances have similar mean values, smoothens and horizontal spatial distributions. We explain these similarities by the fact that the AH and VMM isostatic models assume the same compensation principle (based on a variable depth of compensation). Since the AH scheme assumes a local compensation and a global compensation mechanism is adopted in the VMM isostatic model, the AH isostatic gravity disturbances resemble slightly more a detailed pattern of the ocean-floor relief (see figure 7a), while the VMM isostatic gravity disturbances follow more closely major bathymetric features (see figure 7c).

As stated above, the PH isostatic gravity disturbances are spatially highly correlated with the bathymetric depth (figure 8b). This trend is also 

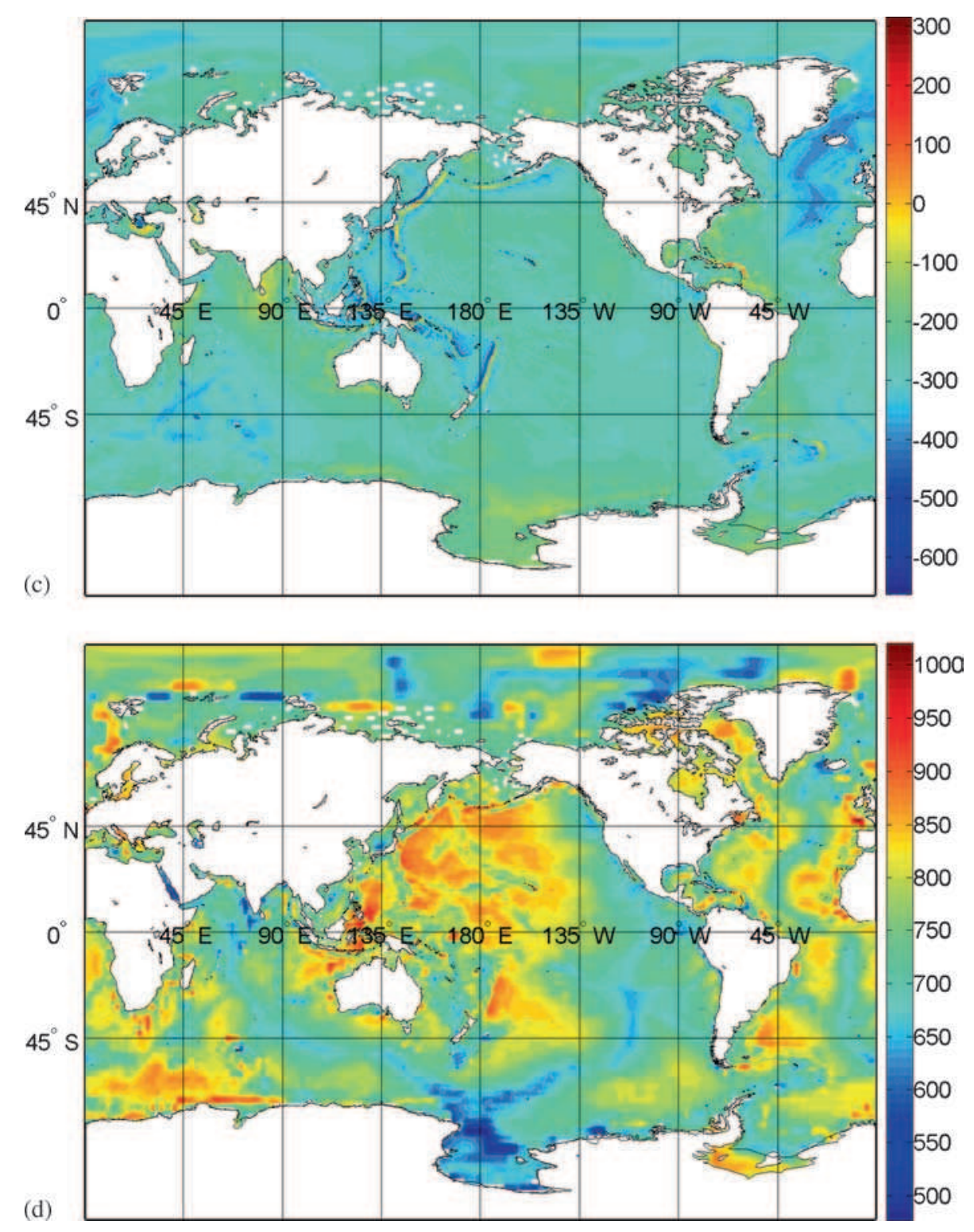

Figure 7. (Continued.)

Table 1. Statistics of the isostatic marine gravity disturbances.

\begin{tabular}{lcccc}
\hline $\begin{array}{l}\text { Isostatic gravity } \\
\text { disturbances }\end{array}$ & $\begin{array}{c}\text { Min } \\
(\mathrm{mGal})\end{array}$ & $\begin{array}{c}\text { Max } \\
(\mathrm{mGal})\end{array}$ & $\begin{array}{c}\text { Mean } \\
(\mathrm{mGal})\end{array}$ & $\begin{array}{c}\text { STD } \\
(\mathrm{mGal})\end{array}$ \\
\hline AH & -496 & 179 & -218 & 46 \\
PH & -513 & 192 & -247 & 125 \\
VMM & -665 & 318 & -264 & 53 \\
CCS & 471 & 1022 & 758 & 63 \\
\hline
\end{tabular}

evident from the gravity map in figure 7(b) which revealed the signature of the ocean-floor relief. The PH isostatic gravity disturbances are typically positive along marginal seas, while negative values prevail over open oceans with extreme gravity minima over oceanic trenches. Compared to the $\mathrm{PH}$ isostatic gravity disturbances, the spatial pattern of the CCS isostatic gravity disturbances is somehow different. Comparison of the gravity maps in figure 7 (b and $d$ ) indicates that the contrast between shallow marginal seas and deep oceanic areas is more pronounced in the $\mathrm{PH}$ isostatic gravity disturbances. This was explained by a high spatial correlation of the $\mathrm{PH}$ isostatic gravity disturbances with the bathymetric depth. Furthermore, another significant difference between these two isostatic gravity disturbances (and also the most intriguing) is the fact that minima of the CCS isostatic gravity disturbances were found along mid-oceanic ridges, while maxima agree with locations of oceanic subduction zones (i.e., along oceanic trenches). In contrast, the $\mathrm{PH}$ isostatic gravity disturbances have opposite trend. To explain these differences, we plotted 

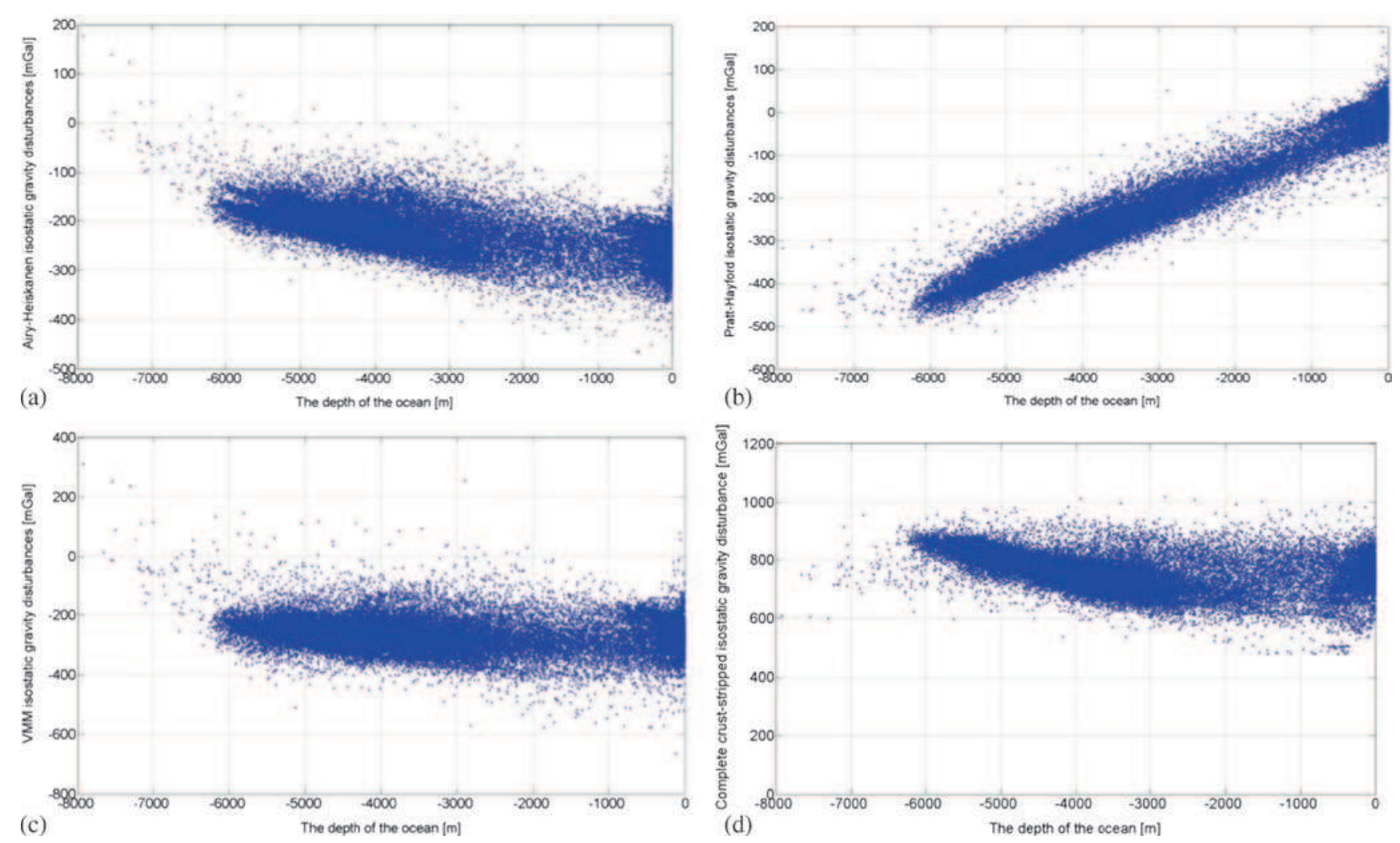

Figure 8. Scatter plots of the isostatic gravity disturbances with respect to the bathymetric depths: (a) Airy-Heiskanen, (b) Pratt-Hayford, (c) Vening Meinesz-Moritz, and (d) complete crust-stripped isostatic gravity disturbances.

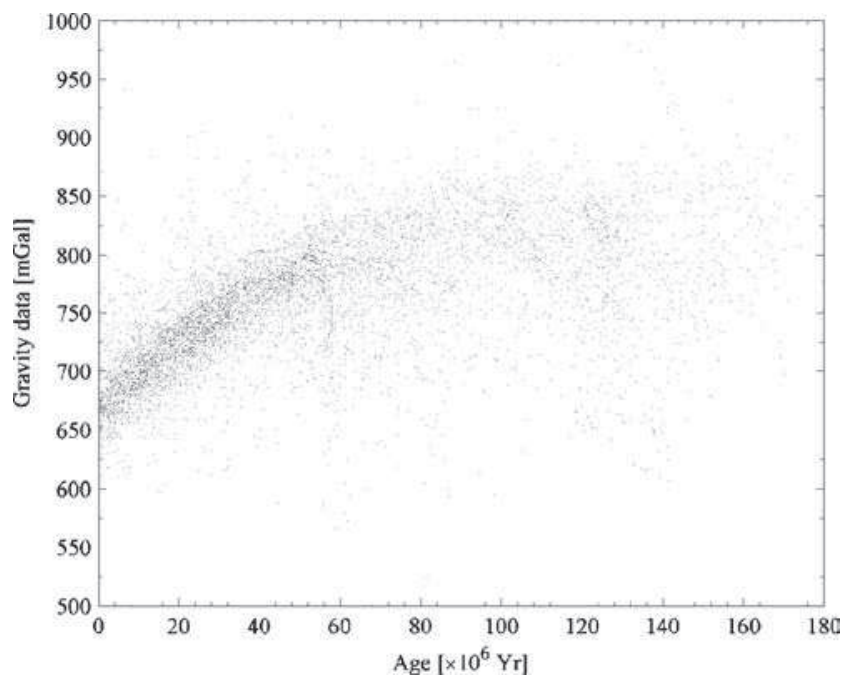

Figure 9. Scatter plot of the complete crust-stripped gravity disturbances with respect to the age of oceanic lithosphere.

(in figure 9) the correlation of the CCS isostatic gravity disturbances (taken only over areas of the oceanic lithosphere) with respect to the ocean-floor age (Müller et al. 2008). We can see that minima of these isostatic gravity disturbances correspond with the youngest oceanic lithosphere along mid-oceanic ridges (cf. figure $7 \mathrm{~d}$ ). The gravity values further increase with age especially within first 80 Myr. Much smaller spatial variations are then seen over the remaining period approximately up to 150 Myr. Maxima of the CCS isostatic gravity disturbances are distributed mainly over oceanic subduction zones characterized by the oldest oceanic lithosphere. The signature of the oceanfloor spreading in the CCS isostatic gravity disturbances was explained by Tenzer et al. (2012e). According to them, the increasing gravity with age corresponds to an increasing density caused by a thermal cooling of the oceanic lithosphere (with the density minima along mid-oceanic ridges and the density maxima along oceanic subduction zones). A horizontal spatial distribution of these isostatic gravity disturbances thus exhibited a thermal state of the oceanic lithosphere. At the same time, an apparent correlation of the CCS isostatic gravity disturbances with the ocean-floor relief is explained by the fact that thermal cooling also causes a contraction of the oceanic lithosphere manifested by an oceanic depending due to an isostatic rebalance of the oceanic lithosphere (e.g., Parsons and Sclater 1977).

\section{Summary and concluding remarks}

We computed and compared four types of the isostatic marine gravity disturbances. The results 
revealed that each applied isostatic scheme provided unique spatial pattern of the marine isostatic gravity disturbances.

The $\mathrm{PH}$ isostatic gravity disturbances are spatially highly correlated with the ocean-floor relief. Since large part of marine areas have not yet been covered by sounding reflection surveys (i.e., the multi-beam echo sounders), the altimetryderived marine gravity data are primarily used to determine bathymetric depths. This is possible because spatial variations of the marine gravity are highly correlated with the oceanfloor relief (in the wavelength band from 15 to $200 \mathrm{~km}$ ). The principles of predicting the oceanfloor topography from satellite-altimetry measurements can be found in studies by Wessel and Watts (1988), Baudry and Calmant (1991), Jung and Vogt (1992), Smith (1993), Sandwell and Smith (1997), and others. The PH isostatic gravity data might thus be suitable for an independent validation of the bathymetric depths predicted using the altimetry-derived gravity data. We note here that this aspect needs to be further verified.

The application of the AH isostatic model provided the smoothest marine gravity field among the investigated isostatic gravity disturbances. In terms of a standard deviation, the $\mathrm{AH}$ isostatic gravity disturbances are more than two times smoother than the $\mathrm{PH}$ isostatic gravity disturbances. These isostatic gravity data are thus suitable especially for an interpolation of marine gravity data.

The VMM and $\mathrm{AH}$ isostatic models provide gravity fields which have a similar smoothness and spatial distribution. These similarities were explained by applying the same compensation principle in both models (based on a variable depth of compensation). Relatively small differences between these two types of the isostatic gravity disturbances are then caused by assuming a global (for the VMM model) instead of a local (for the AH model) compensation mechanism.

The CCS isostatic gravity disturbances exhibited the signature of the ocean-floor spreading controlled mainly by an increasing density due to thermal cooling of the oceanic lithosphere. As consequences, these isostatic gravity disturbances are to be preferably used in studies of the structure and evolution of the oceanic lithosphere.

\section{References}

Abd-Elmotaal H 1991 Gravity anomalies based on the Vening Meinesz isostatic model and their statistical behaviour; Mitteilungen der geodaetischen Institute der Technischen Universtaet Graz, Vol. 72.
Abd-Elmotaal H 1993 Vening Meinesz Moho depths: Traditional, exact and approximated; Manuscr. Geodaet. 18 $171-181$.

Abd-Elmotaal H 2000 Vening Meinesz inverse isostatic problem with local and global Bouguer anomalies; J. Geod. 74 390-398.

Abd-Elmotaal H 2004 Isostatic response of the Earth's crust derived by inverse isostasy; J. Geodyn. 37(2) 139-153.

Airy G B 1855 On the computations of the effect of the attraction of the mountain masses as disturbing the apparent astronomical latitude of stations in geodetic surveys; Trans. Roy. Soc. (London), Ser. B, Vol. 145.

Bagherbandi M, Tenzer R, Sjöberg L E and Novák P 2013 Improved global crustal thickness modeling based on the VMM isostatic model and non-isostatic gravity correction; J. Geodyn. 66 25-37.

Bassin C, Laske G and Masters T G 2000 The current limits of resolution for surface wave tomography in North America; EOS Trans. AGU $81 \mathrm{~F} 897$.

Baudry N and Calmant S 1991 3-D modeling of seamount topography from satellite altimetry; Geophys. Res. Lett. $181143-1146$.

Braitenberg C, Wienecke S and Wang Y 2006 Basement structures from satellite-derived gravity field: South China Sea ridge; J. Geophys. Res. 111 B05407.

Gladkikh V and Tenzer R 2011 A mathematical model of the global ocean saltwater density distribution; Pure Appl. Geophys. 169(1-2) 249-257.

Hayford J F 1909 The figure of the earth and isostasy from measurements in the United States; USCGS.

Hayford J F and Bowie W 1912 The effect of topography and isostatic compensation upon the intensity of gravity; USCGS Spec. Publ., No. 10.

Heiskanen W A and Moritz H 1967 Physical Geodesy; Freeman W.H., New York.

Heiskanen W A and Vening Meinesz F A 1958 The Earth and its Gravity Field; McGraw-Hill Book Company, Inc.

Hinze W J 2003 Bouguer reduction density, why 2.67? Geophysics 68(5) 1559-1560.

Jung W Y and Vogt P R 1992 Predicting bathymetry from Geosat-ERM and shipborne profiles in the South Atlantic ocean; Tectonophys. 210 235-253.

Kaban M K, Schwintzer P and Tikhotsky S A 1999 Global isostatic gravity model of the Earth; Geophys. J. Int. 136 519-536.

Lambeck K 1988 Geophysical geodesy: The slow deformations of the Earth; Clarendon Press, Oxford.

Makhloof A A 2007 The use of topographic-isostatic mass information in geodetic application; Dissertation D98, Institute of Geodesy and Geoinformation, Bonn.

Mayer-Guerr T, Rieser D, Höck E, Brockmann J M, Schuh W-D, Krasbutter I, Kusche J, Maier A, Krauss S, Hausleitner W, Baur O, Jäggi A, Meyer U, Prange L, Pail R, Fecher T and Gruber T 2012 The new combined satellite only model GOCO03s; Abstract presented at GGHS2012, Venice.

Moritz H 1990 The figure of the Earth; Wichmann H., Karlsruhe.

Moritz H 2000 Geodetic Reference System 1980; J. Geod. 74 128-162.

Müller R D, Sdrolias M, Gaina C and Roest W R 2008 Age, spreading rates and spreading symmetry of the world's ocean crust; Geochem. Geophys. Geosyst. 9 Q04006.

Parsons B and Sclater J G 1977 An analysis of the variation of the ocean floor bathymetry and heat flow with age; J. Geophys. Res. 82 803-827.

Pavlis N K, Factor J K and Holmes S A 2007 Terrainrelated gravimetric quantities computed for the next EGM; In: Gravity Field of the Earth (eds) Kiliçoglu A and 
Forsberg R, Proceedings of the $1^{\text {st }}$ International Symposium of the International Gravity Field Service (IGFS), Harita Dergisi, Special Issue No. 18, General Command of Mapping, Ankara, Turkey.

Pratt J H 1855 On the attraction of the Himalaya Mountains and of the elevated regions beyond upon the plumb-line in India; Trans. Roy. Soc. London, Ser. B, Vol. 145.

Rummel R, Rapp R H, Sünkel H and Tscherning C C 1988 Comparison of global topographic/isostatic models to the Earth's observed gravitational field; Report, 388, The Ohio State University, Columbus, Ohio, 43210-1247.

Sandwell D T and Smith W H F 1997 Marine gravity anomaly from Geosat and ERS-1 satellite altimetry; J. Geophys. Res. 102 10,039-10,054.

Sjöberg L E 1998a On the Pratt and Airy models of isostatic geoid undulations; J. Geodyn. 26(1) 137-147.

Sjöberg L E 1998b The exterior Airy/Heiskanen topographic-isostatic gravity potential, anomaly and the effect of analytical continuation in Stokes's formula; J. Geod. 72 654-662.

Sjöberg L E 2009 Solving Vening Meinesz-Moritz inverse problem in isostasy; Geophys. J. Int. 179(3) 1527-1536.

Sjöberg L E 2013 On the isostatic gravity anomaly and disturbance and their applications to Vening MeineszMoritz gravimetric inverse problem; Geophys. J. Int., doi: $10.1093 /$ gji/ggt008.

Smith W H F 1993 On the accuracy of digital bathymetry data; J. Geophys. Res. 98 9591-9603.

Tenzer R and Bagherbandi M 2012 Reformulation of the Vening-Meinesz Moritz inverse problem of isostasy for isostatic gravity disturbances; Int. J. Geosci. 3(5) 918-929.

Tenzer R, Hamayun and Vajda P 2009a Global maps of the CRUST2.0 crustal components stripped gravity disturbances; J. Geophys. Res. 114(B) 05408.

Tenzer R, Hamayun and Vajda P 2009b A global correlation of the step-wise consolidated crust-stripped gravity field quantities with the topography, bathymetry, and the CRUST2.0 Moho boundary; Contrib. Geophys. Geodesy 39(2) 133-147.

Tenzer R, Abdalla A, Vajda P and Hamayun 2010 The spherical harmonic representation of the gravitational field quantities generated by the ice density contrast; Contrib. Geophys. Geodesy 40(3) 207-223.

Tenzer R, Novák P and Gladkikh V 2011 On the accuracy of the bathymetry-generated gravitational field quantities for a depth-dependent seawater density distribution; Stud. Geophys. Geodaet. 55(4) 609-626.

Tenzer R, Novák P, Vajda P, Gladkikh V and Hamayun 2012a Spectral harmonic analysis and synthesis of Earth's crust gravity field; Comput. Geosci. 16(1) 193-207.

Tenzer R, Gladkikh V, Vajda P and Novák P 2012b Spatial and spectral analysis of refined gravity data for modelling the crust-mantle interface and mantle-lithosphere structure; Surv. Geophys. 33(5) 817-839.

Tenzer R, Novák P and Gladkikh V 2012c The bathymetric stripping corrections to gravity field quantities for a depth-dependant model of the seawater density; Mar. Geod. 35 198-220.

Tenzer R, Hamayun Novák P, Gladkikh V and Vajda P 2012d Global crust-mantle density contrast estimated from EGM2008, DTM2008, CRUST2.0, and ICE-5G; Pure Appl. Geophys. 169(9) 1663-1678.

Tenzer R, Bagherbandi M and Gladkikh V 2012e Signature of the upper mantle density structure in the refined gravity data; Comput. Geosci. 16(4) 975-986.

Tenzer R, Chen W and Ye Z 2015a Empirical model of the gravitational field generated by the oceanic lithosphere; Adv. Spac. Res. 55(1) 72-82.

Tenzer R, Chen W, Tsoulis D, Bagherbandi M, Sjöberg L E, Novák P and Jin S 2015b Analysis of the refined CRUST1.0 crustal model and its gravity field; Surv. Geophys. 36(1) 139-165.

Tsoulis D 2001 A comparison between the Airy-Heiskanen and the Pratt-Hayford isostatic models for the computation of potential harmonic coefficients; J. Geod. 74(9) 637-643.

Turcotte D and Schubert G 2002 Geodynamics; 2nd edn, Cambridge University Press, New York.

Vening Meinesz F A 1931 Une nouvelle méthode pour la réduction isostatique régionale de l'intensité de la pesanteur; Bull. Géodésique 29 33-51.

Watts A B 2001 Isostasy and flexure of the lithosphere; Cambridge University Press, Cambridge.

Wessel P and Watts A B 1988 On the accuracy of marine gravity measurements; J. Geophys. Res. 93 393-413.

Wild F and Heck B 2004 Effects of topographic and isostatic masses in satellite gravity gradiometry; In: Proceedings, Second International GOCE User Workshop GOCE. The Geoid and Oceanography, ESA-ESRIN, Frascati, Italy, March 8-10, 2004 (ESA SP - 569, June 2004), CD-ROM. 